\title{
Christianity
}

\section{A Phenomenological Approach?}

\section{Michel Henry}

Journal of French and Francophone Philosophy - Revue de la philosophie française et de langue française, Vol XXVI, No 2 (2018) pp. 91-103

\author{
Vol XXVI, No 2 (2018) \\ ISSN 1936-6280 (print) \\ ISSN 2155-1162 (online) \\ DOI 10.5195/jffp.2018.836 \\ www.jffp.org
}

\section{(oc) EY-NC-NO}

This work is licensed under a Creative Commons Attribution-Noncommercial-No Derivative Works 3.0 United States License.

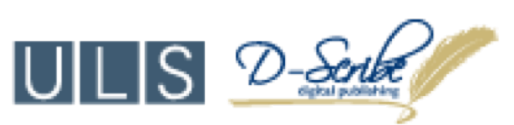

This journal is operated by the University Library System of the University of Pittsburgh as part of its D-Scribe Digital Publishing Program, and is co-sponsored by the University of Pittsburgh Press 


\section{Christianity}

\section{A Phenomenological Approach?}

\section{Michel Henry}

I would like to investigate the possibility of a phenomenological approach to Christianity, with the understanding that this would not be a matter of proposing an interpretation, but that such an "approach" would be able to lead us directly to the heart of Christianity. I will say immediately that a phenomenology that would be able to fill such a task is not the historical phenomenology that was born with Husserl. Only an ideal phenomenology, which would be what is required, would be able to respond to our investigation. This ideal phenomenology is a phenomenology of life.

What must phenomenology become in order to respond to its proper concept? As soon as the question comes to a definition of phenomenology, a hesitation appears between on the one hand its definition as a method and on the other hand its definition via its object. I set aside the definition of phenomenology as a method, namely as a method of intentional elucidation, practicing the phenomenological reduction and trying in this way to get to assured results. In fact, such a definition of phenomenology by its method and notably by the phenomenological reduction has already taken a position on the object of phenomenology: it considers it as an object of thought and also as what must be thought and what is thus susceptible of being. Yet such a conception of the object of phenomenology is already a distortion.

Then what is this object? Phenomenology is the science of phenomena, or rather of their pure phenomenality. In other words, it does not consider things but the way in which they give themselves to us, their mode of givennessnot objects, as Husserl says in Supplement VIII of §39 of the 1905 Lessons on time, but "objects in the How" [Gegenstände im Wie], that is to say in the "How" of their givenness. But one must be even more radical: phenomenology does not truly consider objects in the How of their givenness. Leaving the "objects" aside, it examines this How as such, i.e., givenness itself, the appearing. This appearing must appear as such. For if it did not appear, nothing would be able to appear. If, for example, one calls the appearing "natural light", this light can enlighten anything only if it illuminates itself 
first from itself and in itself. This is hence the object of phenomenology: appearing inasmuch as it must appear as appearing. The object of phenomenology: not only finally in the way in which the things give themselves to us, but the way in which givenness gives itself as such, the way in which pure manifestation manifests itself, the way in which pure revelation reveals itself. The object of phenomenology is the mode of phenomenalization according to which phenomenality phenomenalizes itself.

The mode of phenomenalization of phenomenality is so far only a question. As long as it is not resolved, phenomenology remains plunged into a determination and total obscurity, as was the case for historical phenomenology. As an example, let us consider the principles of this phenomenology.

The first, "as much appearance, so much being" is ambiguous because of its double meaning of the term "appearance" which means both that which appears and its appearing. I will thus formulate the principle as follows: "as much appearing, so much being."

This principle is decisive in that it subordinates any ontology to a prior phenomenology. It is only as appearing and inasmuch as appearing appears that anything whatsoever could be. This decisive subordination of ontology to a prior phenomenology was apparent to the true founder of phenomenology, namely Descartes. Descartes says that "we are only because we think" (Principles I, 8). Let us open here a parenthesis in order to note the inadequate character of the critique Heidegger addresses to the subject of the cogito in Sein und Zeit. Heidegger reproaches Descartes for saying sum, I am, without initially questioning the meaning of being in general. Thus the cogito would admit an unthought presupposition. To the contrary, what is remarkable in Descartes, is that the sum is never posited without being legitimated by something preliminary and it is even more remarkable that this preliminary is not being or the meaning of being but appearing. Let us thus return to our question: as long as appearing, the fact of appearing, remains unilluminated in its pure phenomenological matter, it is being itself that remains entirely undetermined.

Another principle of phenomenology says: "Zu den Sachen selbst!" [To the things themselves!] At stake is thus the mode of access to things in their immediate mode. What gives access to things? Their appearing. It is pure phenomenality, inasmuch as it phenomenalizes itself, that constitutes the mode of access to any conceivable phenomenon. As long as the mode of phenomenalization of phenomenality is not defined, this slogan of phenomenology itself also remains totally undetermined.

The object of phenomenology, the principles that are connected to it, constitute the presupposition of phenomenology. This presupposition is phenomenological through and through, because it is constituted by 
phenomenality. At the same time, it remains phenomenologically totally undetermined to the extent that phenomenality itself remains undetermined.

In any case, if one looks more closely, one notices that behind the phenomenological indeterminacy of the presuppositions of phenomenality and thanks to this indeterminacy, a certain fraudulent conception of phenomenality slides in: namely, the one that presents itself first of all to ordinary thought and that, at the same time, constitutes the most ancient and the least criticized presupposition of traditional philosophy. This conception of phenomenality, which is borrowed from the ordinary perception of the things of the world, is in the final account the appearing of the world itself. This ruinous confusion of the appearing of the world with the essence of any conceivable appearing corrupts the whole development of Western philosophy before the appearing of phenomenology itself. Within Husserlian phenomenology it is its most famous principle, the principle of principles, that exposes this confusion in its full depth.

In $\S 24$ of Ideas I, the principle of principles posits intuition, "any originary giving intuition as a source of right for knowledge." What is given in intuition and makes of it in general a giving intuition is the structure of consciousness that Husserl understands as intentional. Certainly it is fulfilled intentionality that qualifies the concept of intuition, strictly speaking, and this fulfillment must become the object of a specific problematic. Yet, intuition owes to intentionality its phenomenological power, namely that of instituting in the condition of the phenomenon and for that reason of making phenomenality arise. This putting into phenomenality consists in the movement by which intentionality projects itself outside itself by surpassing itself toward its intentional correlate as a transcendent object. It is the placing into distance of this ob-ject in the primitive "out-side" where the intentionality that constitutes phenomenality in its purity surpasses itself. For it is enough to reflect on the concept of phenomenality to see that it leads to an aporia.

Husserl conceives the reality of consciousness as intentionality, as a "relating-oneself-to-a-transcendental-object" in such a way that "relating oneself to" is part of the reality of consciousness—of the cogitatio- "although the object is not part of it." 2 Thus, in itself, by this "relating-itself-to" constitutive of its own reality, consciousness relates itself intentionally to the object and, in its placing outside of it, gives it to be seen, reveals it. Intentionality is this showing that reveals the object. Revelation here is the revelation of the object. Appearing is the appearing of the object in this sense that what appears is the object and also in the sense that, given that what appears is the object, the mode of appearing implicated in this appearing is the mode of appearing proper to the intentional object in making it possible, that is, the "relating oneself to" of intentionality. But what is the mode of appearing of this "relating oneself to" of intentionality itself? 
There is no response to this question in Husserlian phenomenology, nor in the philosophical development that follows after it. That is the reason why the task of revealing the making-seen that reveals the object without ever revealing itself in itself is confined in aporetic fashion to making itself seenas witnessed by the phenomenological reflection implicated in the reduction or the retention that is implied in all reflection. When the question of the selfrevelation of intentionality, that is to say of consciousness, has become that of the self-revelation of the flux, of its Selbsterscheinung, that is, a self-constitution of this flux, then an intentional relation of the flux to itself is demanded by the response. Thus a major crisis takes shape in phenomenology, namely that of phenomenality itself.

This crisis of phenomenality is not unique to phenomenology if it is true that the concept of the phenomenon on which it relies dominates the history of philosophy since ancient Greece. At stake is the phenomenality of the phainomenon, which is to be understood starting from its root phos, light. Appearing thus means coming into this light, which is that of the world. More profoundly, appearing designates coming into the world itself, the arising of the "outside" in such a way that this coming outside of the Outside constitutes the phenomenalization of phenomenality. It is significant that the elucidation of this ecstatic phenomenality, which is in the end understood as temporality, designates this temporality as exteriority itself. "Zeitlichkeit ist das ursprüngliche 'Außer-sich' an und für sich selbst." - "Temporality is the primordial "outside itself" and for itself." And the phenomenality, which illuminates itself accordingly in the temporalization of temporality, is precisely the phenomenality of the world. "Die Welt... zeigt sich in der Zeitlichkeit. Sie 'ist' mit dem Außer-sich der Ekstasen 'da'."—“The world temporalizes itself in temporality. It is with the 'outside itself' of ek-stases that it 'is' 'there'." "s This is not the place to show how the majority of the conceptions of phenomenality implied in our tradition of thought rely on the presuppositions that are evoked here and which have found their systematic elucidation in Heidegger.

If one goes back to the foundation of an ideal phenomenology by Descartes, one finds that Descartes pursues the arising of the original appearing through placing the world and the phenomenality that properly belongs to it out of play. This placing the world out of play results from the doubt that strikes the sensory appearances and the rational truths, both sensory seeing and intelligible seeing, hence all seeing possible in general. And this is the case because, in implicit but decisive fashion, the mode of phenomenalization presupposed by any seeing is deemed doubtful. In this way, while Husserl sets aside everything that is not evident or able to come to evidence, Descartes disqualifies evidence itself.

What, then, remains if everything that I can see with the senses or with the mind is deemed doubtful? At certe videre videor." "At least it seems to me that I see," says Descartes. This statement is only possible if the appearing, in 
which seeing is given to itself, is fundamentally different from the appearing in which seeing sees everything that it sees. This abrupt dismantling of appearing, this doubling-the doubling of givenness itself between the givenness in which seeing is given to itself and the givenness in which all that it sees is given-is reproduced in article 24 of the Passions of the Soul which, at the very moment that it disqualifies the phenomenality of the world with the hypothesis of the dream, posits the absolute existence of the fear that I experience during this same dream. In fact, the fear is absolutely certain even if the appearing of the world is fallacious, because the phenomenality within which the fear is given to itself owes nothing to the dubious phenomenality of the world.

We here encounter again the problematic of ideal phenomenology, namely that the givenness of phenomena is possible only on the condition of a givenness of givenness itself, i.e. of a self-givenness. This self-givenness is life. For life is nothing other than that: what gives itself to itself or what is given to itself, what experiences itself through itself. This is the case because life is this "self-experiencing" in "living" — self-givenness and self-revelation - that each of those in whom life accomplishes itself, knows what in it belongs to life. One does not know it in the way in which we experience the world and its things. Rather, one knows it in the way in which life experiences itself. It is because everyone knows what life is in this way that everyone can speak of it. Meister Eckhart, for example, can say in Sermon \#6: "Among all things there is nothing so dear or so desirable as life. However wretched or hard his life may be, a man still wants to live. ... Yet however wretched life may be, still it wants to live. Why do you eat? Why do you sleep? So that you live. ... Why do you live? So as to live; and still you do not know why you live. Life is in itself so desirable that we desire it for its own sake. Those who are in hell with its eternal torments, whether souls or demons, do not want to lose their life; for even to them their own life is so noble..."'s

Because it is a question of life, here we must avoid an ambiguity. Is life not the object of the burgeoning science of biology? One must respond in the negative: there is no life in biology. I cite François Jacob: "Today, one no longer inquires about life in the laboratories." ${ }^{6}$ This disappearance of life from the field of contemporary biology results from the very foundation of this science, that is to say, from the Galilean reduction that eliminated sensory qualities from nature and, at the same time, the sensibility and life implied in any sensation. More generally, the disappearance of life from the thematic field of science results from the heterogeneity of the appearing of life and from that of the world. Where there is the world, life never shows itself. Where life reveals itself, there is no world.

The question is hence this: what appearing gives in such a way that this givenness accomplishes itself as self-givenness and as life? For it is not any kind of appearing that is able to institute a givenness of this sort. When appearing resides in the making-seen of intentionality and finally in the 
coming outside, this appearing deflects from itself with such violence that it can never give itself but only the other, the world, the in front of [l'en-face]. Thought, especially philosophical thought, the phenomenological method in particular, is all the same only one mode of intentionality. Hence it will not be able to give us life. Our question necessarily remains without response, inasmuch as it is philosophical and falls under thought. The givenness that accomplishes itself as self-givenness and as life, escapes the phenomenological method as intentional method. It escapes us now when we try to think it. This leaves open only one possibility, namely thatindependently of all effort of our thought, outside of our gaze, outside the world-life brings itself into appearing. It phenomenalizes itself from itself according to the phenomenality that is its own and permits it precisely to accomplish itself as this pure self-experiencing of itself, without the gaze, in which consists the living of life.

At this point the question that forms the theme of this talk is reversed. We ask: is a phenomenological approach to Christianity possible? Christianity posits that the essence of reality is Life. According to John, God is Life. If Christianity is organized around this reality of life, then no phenomenological approach is henceforth possible to it. Far from being able to give us access to life, that is to say, to the reality of Christianity, the phenomenological method of intentional elucidation misses it in principle. Only within life is there access to life and by it, that is, conforming to the mode of original phenomenalization according to which life phenomenalizes itself, that is to say, according to which it experiences itself and not anything else-accomplishing itself thus as self-givenness and as self-revelation. In other words, it is only possible to reach life through the way in which life reaches into itself.

The situation that I am describing with regard to the possibility of a relationship to life, concerns the proper relationship of phenomenology to itself. If the true object of phenomenology is life, the question arises as to how one knows how to reach it, because what is considered as its method-the process of elucidation-shows itself incapable of it. The phenomenological method has distorted the true object of phenomenology by turning it into an object of thought. The true object of phenomenology disqualifies its method, because it exempts itself from any thought. The phenomenology of life therefore means anything but applying the phenomenological method to this particular object of life. Phenomenology will not give access to life. Quite to the contrary, life itself, revealing itself to itself, gives itself to us in this selfrevelation, enables us to reach it. It is life that comes first as the self-revelation presupposed by any form of givenness. It is life that comes in the beginning. It does so as the self-revelation that constitutes the beginning itself. This is just as true for the Christian God, who is nothing other than life, as for selfrevelation. God reveals himself in the beginning and as this beginning itself. That is the first given. The phenomenology of life and Christianity are 
congruent to the point that the reality at stake in them is the same and their problems are also the same.

These problems are linked. They arise in light of a constellation that is still unnoticed by the philosophical gaze. From the point of view of classical phenomenology, one would certainly first speak of the problem of the phenomenological status of life. Yet, how can we fail to notice that such a problem merges with the very object of ideal phenomenology, because at stake is precisely the original mode of the phenomenalization of phenomenality. Yet, here what is called into question is not a question or a "problem" — but a response. This response does not follow on the question but always precedes it. Consequently, it is not a theoretical response, one that would be given at the end of a process of thought and by observing this process, in a theoria. To the contrary, it is never given in an observation, but is given to itself in the self-givenness of life. It experiences itself as such in the pathos that constitutes the phenomenality of this experience, its pure phenomenological substance, its flesh. This pathos-filled and non-ecstatic flesh always precedes the manifold ways of raising the question. The congruency of the phenomenology of life and of Christianity is attested within this flesh. It is not only the question of life and of its own phenomenalization, that remains unthought in its originality, but also the relation of life to the living. It is up to Christianity to have initiated such a question, before it could even become a question for the phenomenology of life. In this respect, it is one with a dogma that seems to impose itself on thought like a strange constraint. But this passivity of thought in regard to a dogmatic content goes back to a much more fundamental passivity: the passivity of the living in regard to life. The question common to Christianity and a phenomenology of life, in fact, arises in all its crushing weight, with the question of the relation of life to the living, understood as internal to the process of the phenomenalization of life and, in the end, as identical to it.

In this shared question, it is actually possible to underline one aspect that seems to fall more especially under the dogmatic side and another that seems to fall under phenomenology. This double aspect is revealed to us when, while reflecting on the relationship of life to the living, we remark that it is possible to range in thought so to say in both directions: from life to the living or instead from the living to life. If it is a matter of understanding this relationship starting from life, the dogmatic side probably knows more about it, because it is itself the Word of Life. If it is a matter of starting from the living, i.e. from ourselves, phenomenology can help us. In the interest of time, I will stick here with only one language, which I will strive to render intelligible as much as possible, namely the relationship of life to the living as it is accomplished in the process of the phenomenalization of life.

Life is in fact a process, the eternal process by which it comes into itself, experiences itself, and rejoices in itself. In this way it constantly produces its own essence, inasmuch as this consists and exhausts itself in such self- 
enjoyment. In this way life self-engenders itself constantly. What is experienced in the movement of this self-generation of life, in which it continually come into itself and experiences itself, comes ever anew to the one who experiences it ever anew. Life is a self-movement that experiences itself and does not cease to experience itself in its own movement in such a way that nothing ever detaches it from itself, nothing ever slides outside this selfmoving self-experience.

From the fact that life's coming into self is its coming into the "selfexperiencing of itself," in which it rejoices in itself, it follows that the process of life's self-generation is identically the process of its self-revelation in the form of this joy. Life's coming into itself is thus not only the birth of phenomenality. The manner in which this phenomenality is phenomenalized reveals itself within it in an indisputable way. This revelation reveals itself thus: as pathos and as its affective flesh. That is the reason why nothing other reveals itself within it than itself - that is why life is auto-affection in a radical sense and not hetero-affection by the world. This is what it means to say: experiencing oneself [s'éprouver soi-même]. The original essence of Ipseity is this identity of experiencing and of the experienced. Henceforth this cannot escape us: an essential Ipseity, without which no process of this sort would ever be possible, is implied within the process of life's self-generation as this process of pathos-filled self-revelation in the experience and the joy of self. Inasmuch as the process of life's self-generation as its process of selfrevelation accomplishes itself effectively, as one that is phenomenologically effective, so the essential Ipseity that it generates in this self-generation is also an effective one: it is a singular Self that embraces itself, that affects itself and rejoices in itself. In this way this embrace, in which the Self embraces itself, is not separate from the embrace in which life grasps itself, being simply the way in which it does it. In this way life can embrace and reveal itself to itself in self-enjoyment only by generating in itself this Self that embraces itself as the phenomenological execution of its own embrace of itself. This singular Self, in which life embraces itself, is the First Living.

Here the strange web of relations established between the phenomenology of life and the dogmatic content of Christianity is discovered. This affinity can be read behind the vocabulary.

Christianity calls life God. To the extent that life is a process of selfgeneration, Christianity calls it the Father. The First Living generated in the process of life's self-generation as singular phenomenological Ipseity in which this process is accomplished, Christianity calls the only first-begotten Son. The Son is consubstantial with the Father and paradoxically comes in the beginning, because the self-generation of life implies the generation of the First Living not as its result but in its phenomenological accomplishment and as its very condition. To the extent that the process of life's self-generation is its process of self-revelation in the Self of this First Living, it is the Word, the Logos, precisely the self-revelation of life. Henceforth the Father is revealed 
and experiences himself in the Son, as the Son experiences himself in the Father. The Son is the pathos of the Father just as the Father is the pathos of the Son according to their reciprocal phenomenological interiority constantly affirmed by John. It becomes intelligible in a radical phenomenology of lifeinasmuch as life is revealed in this very phenomenology, due to its radical nature.

The intuitions shared by a phenomenology of life and Christianity can henceforth be expressed as follows: no living without life, certainly, but no life without a living. And that because there is no life without the Ipseity of an actual Self in itself, just as every life is necessarily a living Self, given to itself in the self-givenness of life and in it alone. And that is valid for the living individuals who we are as much as for the First Living.

With regard to us, there is hence a radically new conception of the human advanced. Its novelty and radicality lies in the fact that the human in Christianity is no longer understood-as has always been true and today more than ever-starting from the world but from life. "Son of God" means: generated in the process of life's self-generation and in it alone. The relationship of the human to himself as well as his relationship to the world are thus accomplished according to the mode of phenomenalization in which this process consists. Both a transcendental and an analytic aesthetic are set aside here. The human is not sketched in the world as this flickering and always inaccessible shape, but is invisible-riveted to himself, and all the same crushed against himself, charged with himself, and bearing himself in his pathos-filled corporeality and in his tear-resistant flesh.

The human occurs only generated in life's self-generation. That is, the human is not first of all an ego, "the ego functioning in the final authority," of which the Krisis speaks, "the point-source of intentionality," as Ideas II says. "I am not only for myself but I am myself [Ich bin Ich]," still declares a manuscript from the 1930s. These suggestions have only a derived meaning. Any ego arises from a transcendental birth, if it is an ego or a self only as bearer of a transcendental Self, given to itself only as a Self in the process of life's self-givenness and in its essential Ipseity.

So as never to serve as the principle of its self-affection, but always selfaffected in the self-affection of life, the transcendental Self constitutes no less the essence of the human and thus of every Individual in the human sense. The principle of individuation that leads to this Individual hence has nothing to do with the principle of individuation of which traditional philosophy, common sense, and science speak, a principle determined by space and time, that is, the phenomenological categories of the "world." The first principle of individuation, that is to say, Life, or even the Christian principle, grounds any ipseity and hence any transcendental Self and hence any conceivable human. The second principle of individuation, which individualizes according to its place in space or in time, only concerns things or the human treated as a thing. 
The misconception or negation of the first in favor of mere worldly individuation implies the elimination of the human. This unconscious but overt murder is henceforth implied as an open possibility in scientific discourse about the human. For example, in these statements as consonant with an odious past as with our threatening future-that of pure technology: "Maybe we will also be able to produce at will, in as many exemplars as we wish, the exact copy of an individual, a politician, an artist, a beauty queen, an athlete for example. Nothing would henceforth prevent applying to human beings the process of selection utilized for race horses, for rats in laboratories, or for milk cows."

Yet, if the individual is considered independently of his transcendental birth in the Ipseity of absolute life and hence abstracted from his condition of living transcendental Self, then this leads to his theoretical or actual annihilation. In parallel fashion, when life is no longer grasped phenomenologically as the process of its self-revelation in Ipseity as an essential Self, then this Life is led to its ruin. A significant fact: at the very moment when he violently objects to Kant's philosophy of the representation of the reality of life, Schopenhauer cannot escape the traditional prejudice that reserves the power of manifestation for this representation, that is to say, for the "outside" of the world. Irrepresentable life becomes merely a blind or unconscious force and an anonymous, impersonal life, crushing the individual rather than giving him birth. The incapacity of recognizing the revelation that constitutes the essence of life goes together with the elimination of the Ipseity in which any living transcendental Self, any I and any ego, any conceivable "human" finds his condition. Thus the negation of the phenomenological character of life entails the negation of the transcendental Self, which constitutes the essence of the human-and that not by accident, if all living Self takes birth in the process of phenomenalization of life and nowhere else. This double negation can, for example, be read in Freudianism, but is exposed in a general way in the world of modernity, not only under its theoretical aspect but tomorrow maybe under its practical aspect. In this regard, one may wonder whether the battle undertaken by modern democracy against Christianity can be pursued without damage, to the extent that the values of democracy are just the by-products of Christian values, the rights of man, a replacement of the infinite value of the person, that is to say, of the generation of each conceivable Self in the self-generation of absolute life. Is this objective covenant, concluded under the mask of "neutrality" by democracy with objectivism, scientism, and the unleashing of a technology defined by the elimination of life, compatible with the maintenance of any given value if there is in fact no value in the world and in objectivity but only in life, in it, for it, and by it? Will the concerted refusal of Christianity still be separable from the destruction of democracy itself?

A final question retains our attention for a moment, one that emerges among all the others from the recognized identity between the object of the 
phenomenology of life and that of Christianity. It is that of ethics, or better of the relationship between ethics and religion. Religion, religio, designates a link, namely what links the human to God. It is the link of life to the living. Ethics considers it starting from the living and from their own condition. And that is justifiable to the extent that such a link defines this condition, which is that of any living. In this respect, ethics or religion are thus not superadded questions. Because they proceed from the very condition of the living, they presuppose, as we said, a response that always precedes their arising. This situation is masked because ethics presents itself as a reservoir of exterior prescriptions like a transcendental Law, such that its site is found to be displaced from the outset and its origin forgotten. For Christianity's first and decisive affirmation (whether it is formulated by John, by Paul or by Christ himself) is that of returning ethics to its proper place, within the immanence of the living, turning the Commandment into the Commandment of Life that generates the living in such a way that ethics is no longer anything other than the manner in which the living lives his transcendental birth in such a fashion that he can relive it.

What is most remarkable is that the return of ethics to the radical immanence of the living is one with the affirmation that only action matters. This implies the radical subjectivity of action, a thesis that will be perceived by philosophy only nineteen centuries later, namely by Maine de Biran. Here the phenomenology of life can offer its contribution to Christianity's insight and its paradoxes. According to the thesis of the duality of appearing, everything is double: the body and also action. This is presented on the one hand under the form of an exterior process but in its reality is nothing else than the inner feeling of effort, the suffering deployment of the subjective potentialities of living corporeality, in such a way that the visible appearance is totally different in its phenomenality from the non-ecstatic pathos. Henceforth what shows itself outside can be in contrast to what is accomplished in invisible life. Thus the behavior of fasting can very well be produced by someone who is not fasting-someone with a drawn face and sunken cheeks-the behavior of piety by someone who does not pray, but strikes his chest and bumps his forehead on the ground. Thus the world of Christianity can be one of hypocrisy or of incognito. Yet, where real action is produced, it is given to itself only in the self-givenness of absolute life, under the all-seeing Eye of God, the "Father who sees in secret" (Matt. 6:17).

One of the principal objections addressed to Christianity notably since Hegel and taken up again by Marxism, thus largely determining the ideology of the 20th century, is that Christianity is a flight from reality, into an imaginary Heaven. The phenomenology of life that situates reality in life states what must be thought of this objection. Only the phenomenology of life says much more. It also advances a new conception of the world, which can no longer be reduced to what we see. The true reality of the world is precisely held in life. The world is the lifeworld [Lebenswelt], but in an entirely different 
sense than the Husserlian one. In Husserl, the lifeworld means that the world is given to the sensibility to which in the final instance any possible object is referred, such as scientific idealities. In any case, the world remains a range of transcendence. In a phenomenology of life, to the contrary, the world is doubled. In its radical transcendence in regard to any being and in its Difference with it, the world frees the being that it unveils in the horizon of this Difference. Being is the content of this "world," in such a way that this content is never explained starting from its unveiling in the world. If the light is indifferent to everything that it illuminates, then it has no other power in its regard than the one of unveiling. Moreover not in itself, because it is not constitutive of its interior structures, of its determinations, of its reality. This reality of the content of the world, this content that is incomprehensible and irreducible starting from its exterior appearance, is life. Instead of turning us away from the reality of the world, Christianity leads us back to it. And what is clear is that this reality, whose reality is the pathos-filled flesh of life, has laws, a structure, and a finality radically different from the laws of the world, that is to say, from its phenomenological structures, of space, time, and causality. Thus a realm of reality opens before thought, which, being that of the world, is not forcibly different from what is constituted by the phenomena of the world.

This is hence a new and fundamental epistemological problem of searching a methodology that, notwithstanding this vanishing of life before thought, would nevertheless be able to give us access to it. Truly, such methodologies do not belong only to the future. One could give at least two examples of their spontaneous or explicit realization. The first would be Husserl's phenomenological method itself, but grasped in its final possibility rather than being practiced in a sort of blindness, outside a clear consciousness of this possibility. The second is the extraordinary "critique of economy" practiced by Marx, not a critique, truly, but a genius intuition of the foundation of every conceivable "economy" in life. A reflection on these two methodologies would illuminate their extraordinary affinity.

Nevertheless only in life is there such an effective relationship to life. As regards us, as "humans," such a relationship defines our own proper condition. The irreducibly singular Self that I am, is only given to itself in the self-givenness of life. The constitutive relationship of our condition is hence a movement, the self-transformation of this living generated in the selfgeneration of absolute life, living only from it, and being able to accomplish its own essence only within the essence of this absolute life. The movement of this self-transformation is ethics, its site is religion. The relationship of ethics and of religion offers us a privileged theme where, above all, the essential congruency of a phenomenology of life and of Christianity is discovered.

\section{Translated by Christina M. Gschwandtner}


1 This article was originally published in French in the Annales de Philosophie, Université Saint-Joseph de Beyrouth, vol. 18 (1997): 3-17. Thanks are due to PUF for granting permission to publish the English translation here.

${ }^{2}$ Husserl, Idea of Phenomenology, Third Lesson (1907).

${ }^{3}$ Heidegger, Sein und Zeit, 329 and 365.

${ }^{4}$ Descartes, Second Meditation, AT VII: 29.

${ }^{5}$ Meister Eckhart, "Sermon 6," in The Complete Mystical Works of Meister Eckhart, trans. Maurice O'C. Walshe, revised by Bernard McGinn (New York: Crossroad, 2009). ${ }^{6}$ François Jacob, La logique du vivant (Paris: Gallimard, 1970), 320.

7 Jacob, La logique du vivant, 344; emphasis added. 